\title{
RICARDO PIGLIA: LA FICCIÓN DEL NOMBRE ${ }^{1}$
}

\author{
RICARDO PIGLIA: THE FICTION OF THE NAME
}

\author{
Raquel FERNÁNDEZ COBO \\ Universidad de Almería \\ rfc206@ual.es
}

\begin{abstract}
Resumen: El presente estudio analiza los tres tomos de Los diarios de Emilio Renzi en relación con su obra anterior, dentro de lo que Lejeune llamó "el espacio autobiográfico". Estudiamos de qué modo Piglia encuentra a través del diario y la autobiografía la forma ideal para narrar la experiencia de la vida. El género autobiográfico principalmente le permite al autor de Respiración artificial inventarse a sí mismo a través de tres estrategias fundamentales: la construcción de un linaje familiar y literario; la ficción del nombre propio y la intertextualidad, es decir, la apropiación de otras lecturas no solo como estética sino como ética.
\end{abstract}

Palabras clave: Piglia. Diarios. Autoficción. Intertextualidad. Experiencia.

\begin{abstract}
The present study analyzes the three volumes of Los diarios de Emilio Renzi in relation to his previous work, within what Lejeune called "the autobiographical space". We study how Piglia finds through diary and autobiography the ideal way to narrate the experience of life: the autobiographical genre mainly allows the author of artificial respiration to invent itself through three fundamental strategies: the construction of a family and literary lineage; the fiction of the proper name and the intertextuality, that is, the appropriation of other readings not only as aesthetics but as ethics.
\end{abstract}

Key Words: Piglia. Diaries. Self-fiction. Intertextuality. Experience.

${ }^{1}$ Este trabajo se ha realizado en el marco del trabajo de investigación I+d EDU2015-69924R. 


\section{INTRODUCCIÓN}

Los diarios de Emilio Renzi, obra maestra del escritor argentino Ricardo Piglia, están compuestos por los tres volúmenes subtitulados Años de formación (2015), Los años felices (2016) y Un día en la vida (2017), y se caracterizan por una dialéctica entre pasado y presente que, a su vez, se ve interferida por otros tiempos verbales: por un lado, el tiempo de escritura - siempre situada en el pasado-y, por otro lado, el tiempo de lectura en el acto mismo de rememorar que, a su vez, se divide en dos tiempos: el tiempo de leer a otros — a Pavese, a Brecht, a Sarmiento, etc.y el tiempo de leerse a sí mismo - manifestado en los paréntesis como una intromisión desde el presente- De esa relectura del diario nace, como veremos, uno de los desdoblamientos más complejos que se dan en la escritura diarística: un juego de yos que se extiende ad infinitum. Al yo que vive y al yo que escribe, se añade el yo que corrige y publica a los dos anteriores, pero también un yo que lee otros diarios y filtra la experiencia de su lectura en lo que he convenido en llamar la ficción del nombre.

\section{LOS DOS LINAJES}

Años de formación narra el mito de origen de la escritura y la lectura por alguien que se autodesigna como escritor, pero al mismo tiempo trata también de un relato que forja un nuevo nacimiento adscrito a una doble genealogía. Como el mismo Piglia dijera de Borges en Ideología y ficción, su escritura "se constituye en el movimiento de reconocerse en un doble linaje" (1979: 3): el linaje familiar —en donde la madre y el abuelo serán sus modelos narrativos centrales - y un linaje literario - el de Los Libros y los autores que completan su proceso de "autoformación"-. Al fin y al cabo, toda genealogía literaria se construye sobre una base familiar que define el lugar y la relación con la literatura. No es una novedad en los Diarios de Piglia; es la clave de la construcción del oficio de todo escritor. En su caso, el peronismo de su padre provocará lo que para él fue vivido como un destierro. Un hecho histórico y político que retrata la figura del padre con frialdad y distanciamiento es la causa, en este caso, de su escritura diarística: 


\section{Domingo 8}

Serie A. Medio día nublado con un sol lívido en el aire. Hoy es el cumpleaños de mi padre, la indiferencia de siempre frente a ese hombre golpeado "por la historia", como dice de él mismo. Sintió la furia y el odio político como una cuestión personal, eso era el peronismo para él, una cuestión privada, como si se tratara de ser fiel a un amigo (el peronismo hizo de la política una cuestión sentimental, por eso persiste). Lo llamé por teléfono, siempre trata de parecer eufórico y lleno de proyectos. ¿Cuándo nos vemos? Es nuestro leitmotiv (Piglia, 2016: 55).

Las lecturas e historias de su madre provocan, en cambio, una definición del estilo - una herencia, digamos-. Este doble linaje familiar, a la manera borgiana, especifican las condiciones de su literatura $\mathrm{y}$, al mismo tiempo, la justifican:

Pero mi madre tiene un criterio moral que yo admito. Nunca juzga a nadie que sea miembro de la familia, o mejor, siempre absuelve y comprende a quien sea con tal de que pertenezca al clan. Por ejemplo, si en mi familia hubiera un asesino serial, mi madre diría: "Bueno, siempre fue un muchacho nervioso". De ella aprendí que un narrador no debe nunca juzgar a los personajes de su historia. $Y$ para mi madre y para sus hermanos y hermanas lo fundamental es volver a contar una y otra vez los relatos familiares. Es imposible para mi sintetizar todas las historias que se amontonan entre los cuerpos de estos testigos de la tribu (Piglia, 2015: 131).

La madre - la figura femenina - como una narradora distanciada, al estilo de Faulkner, que jamás juzga, pero también como la máquina de narrar versiones y contraversiones de La ciudad ausente, es la depositaria de la herencia familiar, en donde:

Se cuentan las mismas una y otra vez, y al contarlas y al repetirlas mejoran, se pulen igual que el canto rodado que el agua cultiva en el fondo de los ríos. [...] Mi madre fue - dijo Renzi-, durante años, la depositaria más fiel de las historias de la familia y esas historias 
eran muy buenas porque se sostenian sobre lo personal, habia figuras fijas, por ejemplo mi tio Marcelo Maggi, a quien siempre se regresaba y al que nunca se ha de olvidar (Piglia, 2015: 338).

La historia familiar moldea la forma de su propia vida y también la forma de su literatura. La ficción familiar, por tanto, es el núcleo que ordena sus textos y le otorga una estructura circular, como ya vimos en el capítulo tres: todas las obras pueden leerse como una única obra, en donde se producen variantes y pequeños cambios de posiciones, pero en donde también existen motivos, personajes y ciertas estructuras que se mantienen. Piglia encuentra en la madre el modelo literario perfecto. "Mi madre es, para mí, un modelo de lo que debe ser un narrador. Detallista, minucioso e incapaz de condenar lo que hacen otros" (Piglia, 2016: 161), anota en Los años felices, señalando cierta consciencia de su destino literario.

De su abuelo Emilio heredará el nombre y su obsesión por el "aterrador calendario". El almanaque colgado en la pared había detenido el tiempo el 3 de febrero de 1943, fecha de la muerte de su abuela Rosa. Y su abuelo pasaba las horas sentado mientras contemplaba la fecha congelada. Ese recuerdo - el primer recuerdo que aparece en Años de formaciónmarca el momento original en que Renzi dejaba atrás una infancia presintáctica y pre-narrativa, para percibir la experiencia de la temporalidad ${ }^{2}$. El tiempo había dejado de ser ilimitado e inmóvil en el preciso instante en que, a los diecisiete años, por cuestiones políticas, deben marcharse de Adrogué. En ese momento, Renzi anota en su diario: "Todo lo que hago me parece que lo hago por última vez". Y con esa sentencia, comienza su aprendizaje de un tiempo histórico, lineal y cronológico que intentará

\footnotetext{
${ }^{2}$ Como señaló Blanchot, la indicación de la fecha es conditio sine qua non del diario. El diario íntimo, que parece tan desprendido de las formas, tan dócil ante los movimientos de la vida y capaz de todas las libertades, ya que pensamientos, sueños, ficciones, comentarios de sí mismo, acontecimientos importantes, insignificantes, todo le conviene, en el oren y el desorden que se quiera, está sometido a una cláusula de apariencia liviana pero temible: debe respetar el calendario. Este es el pacto que sella (Blanchot, 1979: 207). Béatrice Didier, por su parte, ha dado cuenta de que la verdadera importancia de la fecha radica en que cada una de las entradas, como receptáculos de la experiencia real, muestran a un hombre verdadero e histórico: "La inscripción temporal del diario me recuerda - dice Didier - que se trata de un tiempo verdadero que ha sido vivido por un hombre verdadero, y ese hombre ha muerto, como yo voy a morir, de verdad, en un tiempo de verdad - y no un tiempo irreal, y por lo tanto triunfante de la muerte que es el tiempo novelesco-_" (Didier, 1991: 175).
} 
comprender en la escritura del diario. Solo cuando ha comenzado a escribir un diario, Renzi puede sentir la pérdida que su abuelo Emilio trataba de restituir en la contemplación de aquel almanaque "detenido [en] la tarde de la muerte" (2015: 15):

\section{Sábado}

Vuelvo a Adrogué y estoy en el tren. Los encuentros con el abuelo Emilio son lo mejor de esa época para mí. Me ha pedido que por el sueldo que me paga me dedique a organizarle su archivo. Quedamos en que pasaré los fines de semana con él. Lo que él llama "el archivo" es una colección desordenada de carpetas y cajas con materiales diversos dedicados a la campaña italiana en la Primera Guerra. Cuando le pregunto cómo los consiguió, me contesta: "Todos estaban demasiado preocupados en el trabajo de sobrevivir en las trincheras como para ocuparse por los documentos y los papeles que yo sustraía para que no se perdieran" (2015: 79).

Años más tarde, cuando Renzi decide ir a la universidad, comienza un nuevo aprendizaje, ya no el del tiempo cronológico, sino su capacidad para dominarlo en lo que, en un principio, su abuelo dispuso en llamar "el archivo", pero después, Piglia decidió llamar "mis cuadernos":

Su vida se podría narrar siguiendo esa secuencia o cualquier otra parecida. Las películas que había visto, con quién estaba, qué hizo al salir del cine; tenía todo registrado de un modo obsesivo, incomprensible e idiota, en detalladas descripciones fechadas, con su trabajosa letra manuscrita: estaba todo anotado en lo que ahora había decido llamar sus archivos, las mujeres con las que habia vivido o con las que había pasado una noche (o una semana), las clases que habia dictado, las llamadas telefónicas de larga distancias, notaciones, signos, ¿no era eso increíble? (Piglia, 2015: 16).

El segundo recuerdo que abre el primer volumen de sus diarios es una escena sobre Borges. O mejor, una escena en la que él imagina que Borges tuvo que ser aquella larga sombra que se inclinó y le dijo que tenía el libro al revés cuando leía, sentado en el umbral de su casa, frente a la estación 
de ferrocarril. "¿A quién sino al viejo Borges — se pregunta Renzi- se le puede ocurrir hacerle esa advertencia a un chico de tres años?" (2015: 15). Esta escena inaugura en Piglia un modo de leer que, obviamente, viene de Borges, pero que adquiere en su poética una importancia vital ligada a lo político, como se ha justificado en el capítulo anterior. Además, debemos tener en cuenta - olvidando un poco la presencia de Borges en la escena- que Piglia no se encuentra leyendo un libro, sino fingiendo que lee un libro. Como Hamlet — "palabras, palabras y más palabras"-, está leyendo un libro vacío y lo que importa no es qué lee sino el acto mismo de leer; la función que tiene en la construcción del mito lo que podemos llamar el oráculo. La mentira, pues, el juego o la "broma mefistofélica" (Piglia, 2016: 8) da comienzo a la historia de su vida como lector.

De esta manera, las dos escenas con las que comienza el relato "En el umbral" manifiestan que, con la intención de "legar una imagen de sí mismo definitiva y satisfactoria para la posteridad" (Alberca, 2012: 158), Piglia elabora un relato autobiográfico de algunas escenas fragmentarias de su vida que de modo forzoso construyen un mito de origen o, como le atribuiría a Borges, "una fábula biográfica" (1979: 4). Y señalamos la palabra forzoso, porque el autor de Adrogué no sigue una continuidad temporal, sino que selecciona aquellos momentos epifánicos que cumplen una función oracular y que, además, en sus cuadernos de madurez serán interpretados como tal: "Es impresionante comprobar cómo yo decidí mi destino ciegamente en esos dos años (1958-1959), aquí en este cuarto con una ventana que da a las ramas del jacarandá plantado, antes de que yo naciera, en la vereda" (Piglia, 2015: 213). Así, Piglia busca de modo retrospectivo y deliberado en su memoria aquellos momentos que pueden justificar el escritor que ha llegado a ser. "¿Cómo se convierte alguien en escritor, o es convertido en escritor?" (Piglia, 2015: 16) es la incógnita que construye su última ficción (la única ficción posible).

En cuanto al linaje literario, en primer lugar, hay deuda clara con Borges, como acabamos de explicar. Piglia anotó en sus diarios que quien sea capaz de conectar a Borges con Arlt habrá ganado (2016: 178) y en Respiración artificial lo llevó a la práctica como tesis fundamental de la novela. Pero, sin duda alguna, consigue llevarlo a la acción en el conjunto de los tres volúmenes que constituyen Los diarios de Emilio Renzi, pues se une - se cruza - la narración genealógica de Borges y el relato de aprendizaje de Arlt. Borges y Arlt son los pilares, digamos, que estructuran 
y le dan forma a los Diarios. Junto a ellos, se sucede "el reconocimiento de los nombres que organizan el linaje literario" (Piglia, 1979 3): Camus, Pavese, Kafka, Sartre, Martínez Estrada, Faulkner, Henry James, Conrad, Balzac, Kierkegaard, Bellow... Se podría hacer una larga lista de las numerosas lecturas que Renzi va acumulando de un modo vertiginoso en su deseo por llegar a ser quien se propone ("Imaginamos lo que pretendemos hacer y vivimos esa ilusión...” [2015: 18]) y, también, del modo en que esas escrituras del pasado son atravesadas por la Historia y la Literatura argentina de su época. Si el linaje familiar le enseña a narrar, el linaje literario le enseñará a leer: a descifrar su propio contexto con la mirada de un extranjero o del que lee a destiempo - fuera del tiempo-_: "Como siempre, leo todo de un autor (hoy las Memorias y, mientras estoy en el medio, El primer círculo) y me apasiono pero cuando la moda ya pasó" (Piglia, 2017: 64):

Mis lecturas en los últimos meses (sobre Joyce y Brecht) me confirman que llevo cinco años de "atraso" (por lo menos) respecto del resto de mi generación. Leo siempre a destiempo y esa lectura es muy productiva, trabajo siempre los libros fuera de contexto, en otras relaciones ligadas a mi propio ritmo y no al aire de la época. Por ejemplo, en Brecht me interesan los ensayos y no el teatro, y en Joyce busco sus formas clásicas y no tengo nada que ver con el fluir de la consciencia que hace estragos en mis contemporáneos. Ser de vanguardia es estar a destiempo, en un presente que no es el de todos (2016: 248).

La conjunción entre la historia política (ficción paterna) y la literatura (ficción materna) marcarán concluyentemente la ideología en la obra de Piglia. Pero a diferencia de los relatos de Borges que mantienen esas dos ficciones del origen por separado (las armas y las letras) ${ }^{3}$, en Piglia se integran sin contradicción como elementos definitorios de su poética:

\section{Sábado}

En la literatura, creo, lo fundamental es tener un mundo propio. En mi caso, ese material es secretamente autobiográfico y depende

${ }^{3}$ A excepción del cuento "El sur". 
de la multitud de historias familiares que he ido escuchando a lo largo de mi vida. De modo que la novela trabaja a partir de una realidad ya narrada y el narrador trata de recordar y reconstruir las vidas, las catástrofes, las experiencias que ha vivido y le han contado (vivido y contado para mí es lo mismo) (Piglia, 2015: 154).

\section{LA FICCIÓN DEL NOMBRE}

Nicolás Rosa afirmó lúcidamente que al mismo tiempo que se crea un mito de familia, se pierde el sujeto en la ascendencia del linaje. "Linajes del recuerdo y recuerdo del linaje, el sujeto se recuerda en el antepasado de los otros pero simultáneamente se olvida, se disuelve en la permanencia de ese pasado o se pulveriza en los nombres de la Historia" (Rosa, 2014: 62). Estas últimas palabras de Rosa hacen eco de las pronunciadas por Luciano Ossorio en Respiración artificial: "Yo soy Ossorio, soy un extranjero, un desterrado, yo soy Rosas, era Rosas, soy el clown de Rosas, soy todos los nombres de la historia" (2001: 61). Más adelante, serán las mismas palabras que leeremos en una carta firmada por Marcelo Maggi: "Compatriotas: Yo soy aquél Enrique Ossorio que luchó incansablemente por la libertad y que ahora reside en la ciudad de Nueva York, en una casa del East River. Ahora ya soy todos los nombres de la historia. Todos están en mí, en ese cajón donde guardo mis escritos" (2001: 69). Todos los nombres están también en el personaje de Munk de El camino de Ida: "Soy Chambige, soy Badinguet, soy Prado, soy todos los nombres de la historia" (2013: 284). Es una cita que Piglia entrecomilla para dejarle ver al lector que es una apropiación, pues la cita le pertenece al filósofo Friedrich Nietzsche, el cual en su Carta a Bürckhardt datada del 6 de enero de 1889, escribió también: "Im Grund jeder Name in Die Geschichte Ich bin" (Todos los nombres de la historia son en el fondo yo). En filosofía, a pesar de que la identidad fue un tema central, la autobiografía como escritura que la problematiza fue algo bastante secundario, a excepción de la obra de Kierkegaard y Nietzsche. El escritor de Adrogué utiliza de Nietzsche la fórmula del nombre propio para renegar del pro-nombre; del yo. Así, los nombres de la historia real hacen del yo una figura hueca y fantasmal. Si para Nietzsche y para Munk, Badinguet, Cambige y Prado son en el fondo yo; para Emilio Renzi, Borges, Sartre, Camus, Faulkner y, en definitiva, todos los nombres que aparecen en sus diarios - y en sus novelas - son en 
el fondo un yo que se pulveriza. "Necesito a los otros para pensar" (2015: 81), anota en su diario. Entonces, ¿quién habla? "Es el lenguaje y no el autor el que habla" (1987: 64), dirá Barthes.

El Yo es, por tanto, la inscripción de una conciencia en el sistema de pensamiento y del lenguaje. Y para objetivarse necesita una ficción. "No ser nunca uno mismo, cambiar de identidad, inventarse un pasado" (2013: 284), afirma Munk. "Siempre supe que el mejor modo de vivir era inventando un personaje y vivir de acuerdo con él" (2015: 252), escribe ahora Renzi. El desplazamiento en la enunciación de un yo a un él, le otorga a Piglia la posibilidad de inventarse con el objetivo de recuperar el significado de la experiencia al convertirse en objeto puro. Eso a lo que llamamos yo, podemos afirmar, solo existe en la ficción de un nombre propio que es siempre otro ("me siento otro, un desconocido, y eso es impagable"), ya sea Emilio Renzi o los escritores a los que lee. "Todo se cifra en el nombre" (2015:223), señala en su entrada sobre El difunto Matías Pascal de Pirandello. Pues "es la condición del equívoco y del cambio de lugar - por eso los títulos donde brilla un nombre propio (¿qué otras novelas tienen el apellido de un varón en la tapa?)", continúa escribiendo Renzi. Su auténtico nombre desaparece en sus cuadernos para dar voz a sus lecturas y, a la vez, hacernos creer que dichas lecturas se originan en él y que las historias de esos textos coinciden — se amalgaman - con su propia historia personal. Y de esta (con)fusión entre el nombre propio y la historia de otros textos nace una ética de vida y un estilo que define la escritura de Ricardo Piglia:

Serie E. Como se ve este cuaderno tiende a marcar sobre todo mi biografía intelectual, como si la vida se fuera dibujando sin otro movimiento que el de la literatura. ¿Y por qué no? Siempre hay que elegir la obra y no la vida, o mejor, la obra construye el modo de vivir (2016: 165).

Como nos hace ver Renzi, el acto autobiográfico genera una temporalidad que es también ficticia: "[...] Cuando uno piensa en sí mismo e intenta reconstruir lo que ha vivido naturalmente, uso una forma narrativa y encadena los acontecimientos con una lógica causal, pero la vida no obedece a esas reglas y todo se da confusamente y al mismo tiempo" (Villanueva, 1993: 167). Y en el intento de inscribir al yo en 
una temporalidad y espacialidad, es decir, de darle un lugar en el mundo literario, Renzi descubre sus faltas - sus pérdidas-, las cuales debe reconstruir a través de una memoria inventada, en donde el hombre pueda ser leído como parte de la historia y de la totalidad del mundo. Es por eso por lo que, en Los diarios de Emilio Renzi, la autobiografía "implica una topoelocutiva de relaciones y no un contrato de lectura" (2016: 167). El proyecto autobiográfico de estos diarios revela el papel privilegiado que representa la escritura en la relación entre el hombre y el mundo. Es por ello también que en su literatura no hay fronteras entre la autobiografía y la ficción; entre literatura y la vida, pues todo confluye en la experiencia personal — anotada en el diario- y se bifurca hacia múltiples vidas posibles - realizadas en sus novelas-.

Darío Villanueva ha propugnado con acierto en su aportación a la teoría autobiográfica que "la clave de la autobiografía no está en la prosopopeya ni en las metáforas" (1993: 167). "Yo la encuentro — dice Villanueva - en la paradoja, en la figura lógica consciente en la unión de dos nociones aparentemente irreconocibles de las que surge, no obstante, un significado nuevo y profundo [...]: realidad y ficción" (1993: 167). Los diarios de Emilio Renzi, es la obra que mejor representa esa dicotomía en su sentido más puro: "Trato de construir mi Literatura haciendo de esa tensión - vida o literatura - el tema de mis de relatos (y también de estos diarios). Construir en el arte y construir en la vida. Dar forma a la experiencia" (2015: 73). Bajo esta consigna los diarios vienen a legitimar la lectura de la totalidad de su obra bajo lo que Lejeune llamó "el espacio autobiográfico" (1994).

\subsection{El espacio autobiográfico}

Cualquier crítico estará de acuerdo en que Los diarios de Emilio Renzi deben leerse mano a mano con su obra de ficción, con la que se relaciona de manera coherente. Los Diarios suponen un elemento transcendental para la crítica en su intento de reconstruir el contexto y la génesis de sus novelas. Anotaciones como las siguientes dibujan el mapa de su escritura desde sus primeros cuentos hasta la publicación de Respiración artificial en 1980:

Si pienso en lo que he hecho en estos años —aparte de la euforia 
que produce el envión de escribir y de encontrar un tono-, no veo muchas variantes. Lo mejor es "Las actas del juicio", una oralidad arcaica, nada realista, basada en el ritmo y en un conjunto de pequeñas escenas narrativas encadenadas por un narrador que las cuenta como si no las entendiera. La misma técnica en "Tierna es la noche", donde también cuento muchas situaciones, con un tono más personal, onda confesión escrita que viene de The subterraneans de Kerouac. Lo mismo sucede con "Una luz que se iba" y con "La pared"; muchos argumentos en una sola historia contada en primera persona. La clave es encontrar ese tono personal pero en tercera persona. El resto de los cuentos del libro tiene la misma estructura, cuentan una situación mientras sucede pero en secreto cuentan otra. (El mejor es "En el calabozo") (Piglia, 2015: 198).

Pero la auténtica riqueza literaria de esos Diarios que formaron parte de un mito de origen incierto pero insinuado a lo largo de toda su producción, reside, a nuestro juicio, en que la experiencia autobiográfica, presentada estratégicamente a través de un pacto ficcional $-\mathrm{y}$ no autobiográfico-, le permite al lector reinterpretar su ficción dentro de un espacio autobiográfico. A través de los paratextos y el resto de referencias extratextuales, el escritor de Adrogué ha ido preparando generando expectativas en el lector:

Un libro que preparo como una obra maestra póstuma y que vengo escribiendo desde los dieciséis años bajo la forma de un Diario [...] pienso ese libro como la continuación de Museo de la novela de la Eterna de Macedonio. Lo que viene después de los prólogos [es decir, su obra] es el diario de un muerto (cit. en Fornet, 2007: 2324).

Así, la historia de su escritura está fracturada y dispersa en la historia de sus novelas. Resulta imprescindible incidir en esta idea a través de las palabras con las que el mismo Piglia resumió la obra de Borges en su breve ensayo "Ideología y ficción":

Formado por una multitud de fragmentos, escrito en la obra, perdido en ella, este relato [el diario] es un lugar de cruce y de condensación. 
En un sentido pareciera que esa es la única historia que Borges [y luego Piglia, añadimos] ha querido narrar, sin terminar nunca de hacerlo: la ha disimulado y diseminado a lo largo de su obra, con esa astucia para falsificar que le es característica y a la que todos hemos convenido en llamar su estilo (1979: 4).

Lejeune ha señalado de manera lúcida en El pacto autobiográfico cómo algunos escritores han diseñado de manera estratégica el modo en que desean que sus novelas sean leídas a través de lo que ha llamado "el espacio autobiográfico". Así, pone como ejemplo la obra de André Gide y François Mauriac y añade algunas citas significativas, de las cuales hemos considerado oportuno incluir la siguiente: "Las memorias - confiesa Gide - no son nunca sinceras más que a medias, por muy grande que sea el deseo de verdad: todo es siempre más complicado de lo que decimos. Tal vez nos acercamos más a la verdad en la novela" (citado en Lejeune, 1991, 29: 59). Continúa explicando Lejeune que el ingenuo intento de hacer ver que la novela es más verdadera y más profunda que la autobiografía es, en realidad, un pacto implícito de lectura en donde se le sugiere al lector que "el orden de la verdad que hay que buscar en las novelas" (59). Piglia, podemos afirmar, se postula en esa "doble jugada": al publicar los diarios bajo el nombre de Emilio Renzi extiende el pacto autobiográfico al conjunto de su obra. Es decir, los diarios vienen a avalar una lectura en clave autobiográfica de su narrativa que, en su ausencia, solo podría instalarse en el campo de la ficción y de la especulación crítica. Y es por ello que probablemente estos diarios puedan no resultar atractivos, como sugerimos anteriormente, para un lector no conocedor de la obra de Piglia, e incluso puedan ser tildados de crípticos e ininteligibles. Pues los secretos (las elipsis), las ausencias, los viajes no incluidos y las partes fragmentarias y abiertas están dirigidas a un lector activo, que convertido en un detective potencial sepa leer en su ficción las huellas de esa escritura personal. Porque "muchas veces lo que había escrito en sus cuadernos, pasaba, como quien dice, tal cual en sus novelas y ensayos, y en los cuentos y relatos que había escrito a lo largo de los años" (Piglia, 2017: 9).

Con la publicación de Un día en la vida (2017), la crítica debe emprender la tarea de releer su obra desde el "espacio autobiográfico" (revelado póstumamente), en donde su obra fictiva "es un mero pretexto — dice Fornet- de su obra verdadera" (2000: 356). Y para ello, la noción 
de intertextualidad será transcendental si queremos reconstruir la historia de las relaciones entre los textos, pues debemos entender esta - siguiendo a Rosa - como "una de las formas por las que el sujeto de la crítica tiende a dar cuenta de los productos literarios en el registro imaginario y simbólico de la ascendencia" (2004: 23). Es decir, es la pregunta por el origen de los textos - ya desarrollada en este capítulo- que "intenta dar cuenta del funcionamiento literario y discursivo, pero que imaginariamente escribe la historia imaginaria de la crítica" (Rosa, 2004: 23). Asimismo, la intertextualidad permite leer en su ficción la verdad de su de su vida. Una operación que hace de la relación entre verdad y ficción el tema cardinal de su escritura. Al respecto, Nicolás Rosa sostendrá que:

Si las novelas son más verdaderas que las autobiografias [...], es porque dicen lo que deben decir y como se debe decir: la verdad no puede ser dicha toda, solo puede decirse a medias y transformada, la verdad siempre se dice indirectamente, y los novelistas son profundos cuando dicen que no dicen, y cuando dicen la forma del no decir, no cuando dicen que dicen y lo dicen. (2004: 44-45)

A luz de estas palabras debemos tener en cuenta que, en nuestro tiempo, existen diferencias claras entre el modo en que se leen sus novelas y sus diarios: mientras en las novelas el mundo personal del escritor se integra en la ficción donde se diluye la importancia de la referencialidad (la verdad), en Los diarios de Emilio Renzi la realidad extratextual y el horizonte de expectativas del lector determina un pacto de lectura "antificticio" (verídico). A pesar de que nunca llega a ser formulado stricto sensu por parte del escritor, el cual rompe el principio de identidad con la ficción del nombre propio. Pero esa sería otra cuestión que hemos justificado previamente. Lo fundamental del espacio autobiográfico es, por tanto, que el diario como "lugar donde están registradas todas las conexiones, el lugar de cruce" (Piglia en Larre y Bajter, 2011: 123), no viene a afirmarse únicamente como la obra maestra, sino como la obra que le otorga el valor de la verdad de una vida a lo que solo era leído como ficción. Con el espacio autobiográfico que sus Diarios construyen, las novelas alcanzan el estatuto de la verdad al que refieren Lejeune y Rosa, pues la verdad siempre está escrita indirectamente; de manera implícita — decía Rosa"en aquello que no dice y en la forma del no decir" (2004: 23). Una vez 
leídos sus cuadernos personales, el lector podrá imaginar o intuir de forma más certera quién es Emilio Renzi en Respiración artificial cuando afirma casi abatido por el tiempo que "Tengo más de treinta años, escribí un libro que cada vez me gusta menos y eso no sería nada, si no fuera porque desde hace más de un año no puedo escribir, quiero decir, todo lo que escribo me parece bosta" (2001: 37). O cuando confiesa:

Historias que uno mismo se cuenta para imaginarse que tiene experiencias o que en la vida nos ha sucedido algo que tiene sentido. Pero ¿quién puede asegurar que el orden del relato es el orden de la vida? De esas ilusiones estamos hechos, querido maestro, como usted sabe mejor que yo. Por ejemplo, siempre me acuerdo con nostalgia de la época en que era estudiante. Vivía solo, en una pensión, en La Plata, solo por primera vez en mi vida; tenía dieciocho años y la sensación de que las aventuras se sucedían una atrás la otra. Una detrás de otra me sucedian las aventuras (al menos lo que yo pensaba que eran las aventuras) en aquel tiempo (Piglia, 2001: 35-36).

Los Diarios nos dejarán vislumbrar incluso quién es Marcelo Maggi cuando escribe que "hay que pensar en contra de sí mismo y vivir en tercera persona" (2001: 111). Además, revelarán la verdad en "aquello que dijo y no sabía que lo decía" (Rosa, 2004: 23) y, al igual que las insistencias y las repeticiones de las series de los amigos, del amor o de la política, el lector podrá ahora, definitivamente, descifrar la escritura del oráculo. El capítulo de "El senador" de Respiración artificial, podrá ser leído como el anuncio de un destino o de una profecía:

Que yo, Ossorio, el senador, pienso en él. Y Marcelo podrá adivinar, a pesar de los muertos que boyan en las aguas de la historia, él, Marcelo, podrá adivinar", dijo el senador, "de qué material está hecho ese pensamiento". Ese pensamiento estaba hecho, dijo, de restos, de fragmentos, de bloques astillados y también del recuerdo de viejas conversaciones. "Fragmentos de esas cartas cifradas que recibo o sueño o que imagino recibir o que yo mismo dicto porque no puedo escribir. Porque debo decirle que ya no puedo escribir. Mis manos, ¿ve?, son garras; yo soy el albatros, mi vuelo es plácido 
sobre las riberas del cimetière marin, pero en la altura mis dedos se han transformado en las garras de ese pájaro que solo puede posarse sobre el agua, sobre la roca que sobresale en medio del océano. Ya no puedo escribir, con estas manos ya no puedo escribir, he perdido", dijo, "la elegancia sacerdotal de mi letra manuscrita. Solo mi voz persiste, cada vez más parecido al graznido del pájaro; solo mi voz persiste y con ella dicto mi respuesta a los mensajes que recibo. Pero ¿a quién? Solo, aislado, haciendo equilibrio con las alas sobre esta roca, ¿a quién podría yo dictarle mis palabras? (2001: 62-63).

El senador es el paralítico, es el escritor con garras en lugar de manos, enclaustrado en una silla de ruedas solo su voz persiste, carcomido, posiblemente, por la ELA (Esclerosis lateral amiotrofia). "Los enigmas siempre tienen que ver con el futuro, con lo que no se sabe - escribirá Piglia en el relato "Un día en la vida"-, con la tensión entre la vejez y la juventud” (Piglia, 2017: 193). Ricardo Piglia no solo es Emilio Renzi, es también Luciano Ossorio, aquel personaje que se pregunta a sí mismo "¿en qué se ha convertido mi cuerpo sino en esta máquina de metal, ruedas, rayos llantas, tunos niquelados, que me transporta de un lado a otro por esta estancia vacía?" (2001: 53). Y es también la nena (Laura) de La ciudad ausente cuando "en aquel momento empezó a tener dificultades con el lenguaje", cuando el lenguaje "se iba volviendo abstracto y despersonalizado" (Piglia, 2014: 21). Tal vez, ahí está el secreto de la literatura, en que solo un lector futuro es el único que puede "descubrir una incomprensible relación entre la literatura y el futuro, una extraña conexión entre los libros y la realidad" (2001: 100):

"A veces", dijo después [el senador], "pienso que toda esa coherencia, todo ese rigor, sus consecuencias implacables, pienso, a veces", dijo el senador, "que todo eso está en mi vida, pero no en cualquier lugar de mi vida, en mi pasado por ejemplo, sino ici même, como en un escenario frente a mí. Un escenario vacio donde se respira el aire helado de las altas montañas. El aire helado, gélido", dijo (Piglia, 2001:53).

Y al final del relato, añade: 
Porque yo, dijo el senador, "conozco mi suerte. Sentado, carcomido, artificial, mi carne metálica se herrumbra a la sombra de estos muros roídos por la blancura de las lámparas eléctricas, y sin embargo, jamás he de perder la esperanza de poder pensar más allá de mi mismo y de mi origen" (Piglia, 2001: 65).

De modo que no resulta extraño que el escritor de Adrogué haya decidido incluir el relato de "El senador" en su Antología personal, pues, como en toda antología, existe una selección y un orden siempre secreto e íntimo. Si, como se dijo, la ironía de Dios le dio a Borges la noche y los libros, a Piglia le ha otorgado la invalidez y el genio de poder pensar más allá de él mismo y de su origen. "La enfermedad como garantía de lucidez extrema" (Piglia, 2017: 294), anota de forma sentenciosa en 2015 y, después, escribe las últimas palabras de sus Diarios publicados:

Para no despertar, he decidido grabar algunos mensajes en voz alta en una diminuta grabadora digital que reposa en el bolsillo alto de mi capa, ¿o de mi caparazón?

Si uno puede usar su cuerpo, lo que dice no importa.

El genio es la invalidez (2017: 294).

Palabras escritas en tiempo presente, aforismos, donde no se explica nada porque todo estuvo dicho en el texto invisible desde el origen (recordemos de nuevo: "la expresión mi cuerpo me es ajeno abundaba en sus diarios" [2015: 343]), desde las cartas del porvenir de Enrique Ossorio, al cual acudimos ahora para recordar cuál es el secreto y la lección que nos enseña la literatura de Ricardo Piglia:

Así, yo escribiré sobre el futuro porque no quiero recordar el pasado. Uno piensa en lo que vendrá cuando se dice: ¿Cómo puede ser que no haya podido ver entonces lo que ahora parece tan evidente? ¿Y cómo puedo hacer para ver en el presente los signos que anuncian la dirección del porvenir? Sobre esto y también sobre mi vida he comenzado a reflexionar y por eso les escribo. Pronto escribiré mi Autobiografía (2001: 70). 
"Cuando la novela se apropia de la factualidad de la autobiografía y de la historia - postula Alberca-, el género novelesco se renueva o se enriquece" (2009: 12). Una afirmación que resulta incuestionable en el caso de Ricardo Piglia, pues el modo en que la factualidad ha ido dominando a la ficción hasta borrar sus fronteras es una característica propia que define su estilo. "Todo puede ser parte de la novela que escribo — anota Renzi-. La novela y la vida van juntas, siempre es la misma escisión. Será mejor decir: "La novela de una vida" (Piglia, 2016: 361).

\subsubsection{Hombres de acción}

Por otro lado, la autoficción en la obra de Piglia, también nos ayuda a responder a la cuestión del origen, esencial en su poética, pues se pone en marcha con ayuda de uno de sus mecanismos de construcción fundamentales: la intertextualidad. Con ella, el escritor puede ejecutar "las articulaciones de los ritos de parentesco textual" (Rosa, 2004: 28):

Los textos que tendemos a valorar dentro de la autoficción - dice Piglia - son aquellos que han intentado crear una forma, trabajar con una forma, ver si se podía desarrollar una forma narrativa en la que pudieran entrar más cosas de las que habitualmente entran en un relato de ficción. Es cierto que esa tendencia a salirse de la ficción, incluso a salirse del arte, tiene como primera consecuencia la idea de la crítica al estilo, en el sentido de que el estilo no importa, que la cuestión es la sinceridad del sujeto, la capacidad del sujeto de establecer una conexión (Piglia en Larre y Bajter, 2011: 132).

Así, la autoficción como una forma que le permite las conexiones entre realidad y ficción y, al mismo tiempo, definir su paternidad textual y sus problemas: desde qué tradición leer y cómo narrar esa tradición, son cuestiones que articulan el espacio de lectura y ordenan la forma del relato. Piglia lee desde la ficción y, desde este lugar, desaparece la "zona de borde" (Gerbaudo). Lo que hace lo aprende fundamentalmente de los escritores imaginarios:

Por ejemplo, Stephen Dedalus o Nick Adams. Leo sus vidas como forma de entender de qué se trata. No me interesa inspirarme en 
los escritores "reales". El desprecio de Dedalus por la familia, la religión y la patria será el mío. Silencio, exilio y astucia. Escribía un diario (como yo). Leía filosofia (Aristóteles, San Agustín, Giordano Bruno, Vico). Tenía una teoría extraordinaria sobre Hamlet y la discute en el capitulo de la biblioteca de Ulises. Le gustaban las chicas de mala vida (como a mí). Se fue a Paris para escapar del mundo familiar (como yo me fui a La Plata), quería ser un escritor y que sus cuentos y epifanías se mandaran a todas las bibliotecas del mundo (si él muriera). Admiraba y fue a visitar a Yeats, un gran poeta, como yo admiro y quiero conocer a Borges (Piglia, 2015: 60-61).

Emilio Renzi nace de la lectura y define su identidad a través de estos escritores imaginarios y de personajes literarios caracterizados por una fuerte voluntad de ser, pero sobre todo, de ser otro. En este caso, la voluntad de Renzi es ser el hombre moral por encima de el hombre de letras, es decir, aquel que Tardewski describió en Respiración artificial como el hombre que "sabe que el más alto de los bienes no es la vida, sino la conservación de la propia dignidad. Y él supo — refiriéndose a Enrique Ossorio - hasta el fin vivir de acuerdo con sus principios". (Piglia, 2001: 216). Esa voluntad de ser quien imagina que debe ser y de vivir de acuerdo con esos principios morales hasta el final de su vida, es el tema fundamental que conecta toda su obra desde lo que hemos llamado siguiendo a Lejeune - "el espacio autobiográfico". "Había preferido su obra, digamos así, a su propia vida y había pagado un precio altísimo, pero su ilusión había seguido intacta hasta el final", dice el narrador de Blanco nocturno sobre Luca Belladona (2010: 280). De esta manera, "la elección ciega, segura de dejarlo todo, escapar de cualquier lazo familiar" (Piglia, 2017: 59) por la literatura es traslada a los personajes de sus novelas. Recordemos el último gesto de Cesar Pavese tan comentado por Piglia, el Che Guevara como el último lector, las incisivas alusiones a Gay Gatsby, a Lord Jim, pero también a su personaje de Tom Munk, "esa suerte de Quijote que primero lee furiosa e hipnóticamente las novelas y luego sale a vivirlas" (Piglia, 2013: 232). Todos ellos son lectores que, como Piglia, "pagan con su vida la fidelidad de lo que piensan" (Piglia, 2014: 292). Así, anotará en el diario de 1966: 
A la vez es un gran tema novelístico: Lord Jim de Conrad, que trata de cambiar el pasado, regresar al día en que actuó como un canalla y cambiarlo. Borges tiene un relato parecido que se llama "La otra muerte", un soldado que actuó como un cobarde en una batalle hace un pacto fáustico y vuelve al combate para morir en él como un héroe. Es también el tema de El gran Gatsby de Fitzgerald: un hombre pobre, que ha sido rechazado por una mujer en el pasado, se enriquece empecinadamente para volver a encontrar a la chica siendo un hombre de fortuna y logar así cambiar el destino. En definitiva, se trata de pensar el pasado con las categorías que usamos para imaginar el futuro. Lo posible anterior (2015: 242).

Véase ahora este otro texto de El camino de Ida, en que el narrador habla sobre el personaje de Munk:

La decisión de cambiar de vida: ése es el gran tema de Conrad. En Lord Jim, el héroe que en un momento de cobardia ha saltado de su barca a punto de naufragar, decide modificar el pasado y convertirse en un hombre valiente, igual que Jay Gatsby, que compra una mansión en la bahía frente al mar y hace fiestas para seducir a una muchacha que años antes lo había abandonado [...] (2013: 233).

Como dice Renzi sobre el modus vivendi de Munk, "la cuestión no era cómo hay pensar lo que se vive, sino como hay que vivir para poder pensar" (2013: 194). El deseo de ser fiel a los principios conlleva la voluntad de cambiar el pasado y, así, poder construir un yo verdaderamente fijo, inmutable e intransigente. En Un día en la vida anota:

Había pensado que en el final de la novela, como el gran género post-trágico, en este mundo del que habian desertado los dioses, el héroe se convertía o moría, es decir, se suicidaba (como Quentin Compson) o entraba en razones (Alonso Quijano al final de su vida), mientras él, en cambio, no pensaba transigir; $y$, en cuanto al suicidio, había pasado varias veces por él sin éxito, entonces mejor dejaba la historia de su vida en ese punto [...] (2017: 162; el énfasis es nuestro). 
Emilio Renzi se afirma como un yo que no piensa transigir, que asume ese mandato atado a una oscura convicción (Piglia, 2017: 166) $\mathrm{y}$, entonces, su gesto último no es el suicidio, sino la publicación de sus diarios corregidos, recortados, etc. En definitiva, editados para grabar una imagen de sí que él mismo ha diseñado para la posteridad. En cuando Renzi "empezó a percibir que era varias personas al mismo tiempo. Por momentos, un fracasado y un inútil, pero, al leer luego un cuaderno escrito cinco años antes, descubría a un joven talentoso, inspirado y ganador" (Piglia 2017: 11), su fin último consistió en llegar a ser ese joven, es decir, en convertirse, como señalamos, en precursor de sí mismo. "El sujeto de la investigación era él mismo, el sí mismo, dijo con una carcajada", (2017: 11). El escritor que se toma a sí mismo como modelo.

$\mathrm{Si}$ "El oficio de vivir (que alguien llamó con malicia El oficio de morir) no es en el fondo más que una lenta construcción de ese tránsito: un trabajo empecinado por convertir el pensamiento en acción" (2015: 144) - escribe Piglia sobre Pavese-, Los diarios de Emilio Renzi son también, del mismo modo, "un trabajo empecinado por convertir el pensamiento en acción"; por mostrarle al lector el mayor "hombre moral" que ha dado nuestra Historia de la literatura occidental: aquel que deseó ser escritor y construyó toda una vida dentro de la ficción. "En definitiva eso es la intertextualidad - diría Barthes — : la imposibilidad de vivir fuera del texto infinito, ya sea Proust o el diario o la pantalla o el televisor: el libro hace el sentido, el sentido hace la vida" (cf. El placer del texto). Con la publicación de los Diarios, Emilio Renzi cambia el pasado de Ricardo Piglia ("La suprema impostura está en el hecho de escribir estos cuadernos”, podemos leer en Años de formación, 58). Con ello, parece entrar de un modo magistral en la esfera de hombres que como el Gran Gatsby, Cesare Pavese, Lord Jim, Che Guevara, Luca Belladona, Tomas Munk o el mismísimo Don Quijote de La Mancha, actúan de acuerdo a las novelas que han leído y, al hablar de otros, hablan siempre de ellos mismos.

\section{CONSIDERACIONES FINALES: LA FORMA DE UNA VIDA}

En conclusión, Los diarios de Emilio Renzi nos permiten hablar del “espacio autobiográfico" (Lejeune) en la obra de Ricardo Piglia, el cual 
no puede interpretarse sin tener en cuenta el contexto argentino del autor y sus años de formación. No olvidemos tampoco que es historiador de formación y no entiende al sujeto fuera de la historia. Como bien apuntó Adolfo Prieto en su célebre estudio La literatura autobiográfica argentina, "una compresión de sí mismo, en una etapa determinada de la vida, es, necesariamente, una comprensión respecto de los demás” (2003: 14). Así, se hace reflejo en ese mapa de lecturas de las teorías de Sartre, Williams, Benjamin, Lukács o Marx, entre otros. Lecturas que impulsan la revisión de una tradición y que determinarán nuevas formas de lectura y escritura donde la autoficción es una fuerza centrípeta que elabora un programa narrativo único, siempre con la colaboración de un lector que recupera el sentido perdido en el acto mismo de la lectura:

Obligado a traducir su vida en lenguaje, a elegir las palabras, ya no se trata de la experiencia vivida, sino de la comunicación de esa experiencia, y la lógica que estructura los hechos no es la de la sinceridad, sino la de lenguaje.

Aceptada esta ambigüedad, es posible intentar descifrar un texto autobiográfico, se trata, en definitiva, de rescatar las significaciones que una subjetividad ha dejado caer, ha iluminado en el acto de contarse; espejo y máscara, ese hombre habla de si al hablar del mundo y a la vez nos muestra el mundo al hablar de sí mismo (2015: 336).

Como ha escrito Piglia en sus Diarios de forma insistente, "la literatura y la vida van juntas". Desde esta óptica, el cuaderno de escritor como forma inicial de la escritura, pero también como obra última es, sin duda, el gran aporte de Ricardo Piglia a la Historia Literaria. Los Diarios intentan resolver la gran pregunta que siempre se hizo Piglia: cómo narrar fuera de los géneros. No obstante, debemos tener en cuenta que "narrar fuera los géneros" implica que los cambios genéricos se realicen dentro un sistema literario reconocido. Tinianov en "Una evolución literaria" explicaba acertadamente que "no podemos [...] definir el género de un trabajo si está aislado del sistema" (cit. en Bruss 1991: 63) ${ }^{4}$. Si Los

${ }^{4}$ El texto de Tinianov es fundamental en la poética pigliana, pues sin sus ideas acerca de la evolución literaria no podemos comprender las operaciones de lectura del escritor argentino, los cambios 
diarios de Emilio Renzi consiguen su pretensión de narrar fuera de los géneros, es una decisión que debe tomar el lector. Lo que el lector no podrá negar es que, durante mucho tiempo, la autobiografía y los diarios han sido excluidos del "selecto club de los géneros de ficción" (Alberca, 2012: 153). Así, dice el narrador de Los años felices: "Prefiero seguir con la ficción, escribir mi novela de aprendizaje (hay pocas en este país: El juguete rabioso y La traición de Rita Hayworth). El único inconveniente es que detesto las autobiografías y tendría que escribir la novela en tercera persona" (Piglia, 2016: 389).

Paul de Man también hizo hincapié en que "comparada con la tragedia, la épica o la poesía lírica, la autobiografía siempre parece deshonrosa y autocomplaciente de una manera que puede ser sintomática de su incompatibilidad con la dignidad monumental de los valores estéticos" (1991, 29: 116). Asimismo, Piglia se suma a estas consideraciones cuando escribe en 1968:
Martes
En la biblioteca nacional paso la tarde revisando viejos libros, armando una versión nueva del concepto de autobiografía. Nueva porque imagino los escrito unidos por el género y no por la noción contingente de "literatura". Las escrituras personales exceden esa categoría y se proponen, de hecho, como testimonios. La otra cuestión es que habitualmente se considera literarios solo a los textos de ficción (sea cual sea su orientación) (Piglia, 2015: 334).

Desde esa posición, la autoficción podría interpretarse como el intento de legitimar la autobiografía dentro de los géneros de creación, y no únicamente factuales. Lo que ha variado en la evolución del género sería, principalmente, "el valor literario otorgado al género" (Bruss, 1991: 65). De hecho, algunos teóricos como Villanueva o escritores de la talla de Marcel Schwob han defendido el carácter creativo del género ${ }^{5}$. El error de

producidos en los modos de narrar en la novela o con qué mecanismos se consigue transformar un género en otro. Tinianov escribía: "El estudio de los géneros es imposible fuera del sistema dentro del cual y con el cual están en correlación. La novela histórica de Tolstói entra en correlación no con la novela histórica de Zagoskin sino con la prosa de su tiempo" (en Todorov, 1978: 95).

5 "La autobiografía como género literario posee una virtualidad creativa, más que referencial. Virtualidad de poiesis antes que de mímesis. Es, por ello, un instrumento fundamental no tanto 
pensar que un biógrafo debía actuar como un historiador, "nos ha privado de retratos admirables" (Schwob, 1998: 30) ${ }^{6}$. Así, Los diarios de Emilio Renzi, contribuyen, por un lado, a colocar las escrituras personales en el altar de la sancta sanctorum de la literatura y, por otro lado, a abolir las fronteras entre la literatura y la vida, señalando su virtualidad creativa por encima de sus características factuales:

El diario es un poco el laboratorio de la ficción. Siempre digo que voy a publicar tres o cuatro novelas de mi vida para justificar la publicación de ese diario que se ha convertido en el centro de mi escritura. Me convertí en escritor, se podría decir, para justificar un diario (Piglia en Costa, 1986: 41).

En conclusión, con la publicación del último de sus Diarios, el laboratorio del escritor ha dejado de ser un lugar de experimentación para ser la obra misma. El desplazamiento y la duplicidad del nombre y los juegos paratextuales donde Piglia y Renzi conviven en un mismo espacio (la portada) tienen un objetivo claro: introducir la vida del autor (real) dentro de su proyecto ficcional. Y, de ese modo, darle forma a una vida, pero "qué clase de texto es el informe de una vida" (Bruner y Weisner, 1998: 178):

La forma de una vida - postularon Bruner y Weisner - es tanto una función de las convenciones de género y estilo en las que se expresa como lo es, por asi decirlo, de lo que "sucedió" en el curso de esa vida. Y los momentos cruciales en una vida no son proyectados por hechos reales sino por las revisiones efectuadas en el relato que no ha estado usando para contar sobre la vida y el yo, [...] (1998: 177-178).

para la reproducción cuanto para una verdadera construcción de la identidad del yo" (Villanueva, 1991: 212).

"'Por desgracia, los biógrafos han creído de ordinario que eran historiadores. Y así nos han privado de retratos admirables. Han supuesto que solo podía interesarnos la vida de los grandes hombres. El arte es ajeno a esas consideraciones. A ojos del pintor, el retrato de un hombre desconocido de Cranach tiene tanto valor como el retrato de Erasmo. Ese cuadro es inimitable, pero no por el nombre de Erasmo. El arte del biógrafo consistiría en dar el mismo valor a la vida de un pobre actor que a la vida de Shakespeare" (Schwob, 1998: 30). 
Piglia encuentra una solución a través del diario y la autobiografía, pues estos géneros fundan su radiografía en el mito. El género autobiográfico principalmente le ha permitido al autor de Respiración artificial inventarse a sí mismo a través de tres estrategias fundamentales: la construcción de un linaje familiar y literario; la ficción del nombre propio y, la intertextualidad, es decir, la apropiación de otras lecturas no solo como estética sino como ética. Muchos otros escritores también encontraron en el mito la forma para sus novelas. Joyce ubicó el Ulises en un solo día y Piglia, siguiendo esa forma externa, ha querido dar a conocer lo que pudo haber sido su vida ordenando el material auténtico de sus cuadernos en la forma, aparentemente sencilla, de un día, "una jornada entera que encerrara, en sus horas, varios tiempos" (2017: 162)7. Porque a veces - pensaba Renzi- "la verdad de su destino, que hacía ver su proyecto de convertirse en un escritor" (2017: 161) le había llevado toda una vida a buscar una forma literaria y también un motivo que justificara la publicación de su verdadera obra para que fuera leída con el mismo fervor con el que se puede leer una novela. Se trata, al fin y al cabo, de intentar responder a la pregunta formulada por Wittgenstein: “¿Por qué una forma de vida no habría de culminar en una expresión de fe en el Juicio Final?" (1992: 135):

Entonces ahi también la relación literatura-vida pasa por devolver esa noción que le da a la vida una forma, una armonía, eso que la vida no tiene. Por suerte ¿no?, porque en la vida nunca sabemos bien cuándo terminan las cosas, todo se da al mismo tiempo, no hay una unidad. Pero yo, como soy un arcaico y ya envejeci muchísimo, pienso sin embargo que ese es el sentido de la literatura: nos hace hacer de la experiencia del final, la experiencia de la forma (en Larre y Bajter, 2011: 132).

\footnotetext{
${ }^{7 " C C u a n t o ~ m a ́ s ~ s e n c i l l a ~ l a ~ f o r m a, ~ m a ́ s ~ c o m p l e j o ~ e l ~ l i b r o, ~ ¿ n o ? ~ N o ~ d i j o ~ l a ~ f o r m a ~ v a ~ a ~ s u r g i r ~ d e l ~}$ material, sino que hizo esa elección, frecuente en la literatura de los cincuenta. Un mito es un modo de darle forma a un material que se debe adaptar a esa forma. La tradición más firme de la literatura dice que el material tiene que decidir la forma que tiene, que no es el caso del diario, que tiene la forma de un día detrás del otro" (Piglia en Larre y Bajter, 2011: 132).
} 


\section{REFERENCIAS BIBLIOGRÁFICAS}

ALBERCA, M. (2009). "Es peligroso asomarse (al interior). Autobiografía vs. Autoficción”. Rapsoda. Revista de Literatura 1, 1-24 (también en https://webs.ucm.es/info/rapsoda/num1/studia/alberca.pdf [05/04/2019]).

(2012). "De la autoficción a la antificción. Una reflexión sobre la autobiografía española actual". En El yo fabulado. Nuevas aproximaciones críticas a la autoficción, A. Casas (ed.), 149-168. Madrid. Frankfurt am Main: Iberoamericana Vervuert.

BARTHES, R. (1974). El placer del texto. Lección inaugural. Madrid: Siglo XXI.

(1987). "La muerte del autor". En El susurro del lenguaje, 65-72. Barcelona: Paidós.

BLANCHOT, M. (1979). El libro que vendrá. Caracas: Monte Ávila.

BRUNER, J. y WEISNER, S. (1998). "La invención del yo. La autobiografía y sus formas". En Cultura escritura y oralidad, D. Olson y N. Torrance (comps.), 177-202. Barcelona: Gedisa.

BRUSS, E.W.(1991). “Actos literarios”. Anthropos: Boletín de información y documentación (Número dedicado a: La autobiografía y sus problemas teóricos. Estudio e investigación documental) 29 [extra], 62-79.

COSTA, M. (1986). "Entrevista a Ricardo Piglia". Hispamérica 44, 39-54. COLONNA, V. (2004). Autofiction \& autres mythomanies littéraires. Auch: Tristam.

DIDIER, B. (1991). Le journal intime. Paris: PUF.

DE MAN, P. (1991). "La autobiografía como desfiguración". Anthropos: Boletín de información y documentación (Número dedicado a: La autobiografía y sus problemas teóricos. Estudio e investigación documental) 29 [extra], 113-118.

FERNÁNDEZ, R. (2017). "Los diarios de Emilio Renzi: una lectura en busca de la experiencia perdida". Castilla. Estudios de literatura 8, 62-97 (también en https://doi.org/10.24197/cel.8.2017.62-97 [05/04/2019]).

FORNET, J. (2000). "Un debate de poéticas: las narraciones de Ricardo 
Piglia”. En Historia crítica de la literatura argentina, E. Drucaroff (dir.), vol. 11, "La narración gana la partida", 345-359. Buenos Aires: Emecé Editores.

(2007). El escritor y la tradición: Piglia y la literatura argentina. Buenos Aires: Fondo de Cultura Económica.

GERBAUDO, A. (2009). "Literatura y enseñanza”. En La investigación literaria. Problemas de una práctica, M. Dalmaroni (ed.), 158181. Santa Fe: Editorial UNL.

LARRE, A. y BAJTER, I. (2011). "En el origen de un diario siempre hay una pérdida. Diálogo inacabado con Ricardo Piglia”, 117135. Departamento de Investigaciones Biblioteca Nacional. Recuperado de http://bibliotecadigital.bibna.gub.uy:8080/jspui/ bitstream/123456789/33598/1/Diario_inacabado_Roberto_ Piglia.pdf [15/02/2018].

LEJEUNE, P. (1991). "El pacto autobiográfico". Anthropos: Boletín de información y documentación (Número dedicado a: La autobiografía y sus problemas teóricos. Estudio e investigación documental) 29 [extra], 47-62.

(1993). "Una autobiografía bajo la constricción"). Le Magazine littéraire, 316.

(1994). El pacto autobiográfico y otros estudios. Madrid: MegazulEndymión.

MAN, P. de (1991). "La autobiografía como desfiguración". Anthropos: Boletín de información y documentación (Número dedicado a $L a$ autobiografia y sus problemas teóricos) 29 [extra], 113-118.

PIGLIA, R. (1979). "Ideología y ficción". En Punto de Vista (Buenos Aires) 2, 3-6.

(2000). Formas breves. Barcelona: Anagrama.

(2001). Respiración artificial. Barcelona: Anagrama.

(2010). Blanco nocturno. Barcelona: Anagrama.

(2013). El camino de ida. Barcelona: Anagrama.

(2014). Antología personal. Barcelona: Anagrama.

(2015). Los diarios de Emilio Renzi: Los años felices. Barcelona: Anagrama.

(2016). Los diarios de Emilio Renzi: Años de formación. Barcelona: Anagrama.

(2017). Los diarios de Emilio Renzi: Un día en la vida. Barcelona: 
Anagrama.

PRIETO, A. (2003). La literatura autobiográfica argentina. Buenos Aires: Centro Editor de América Latina.

ROSA, N. (2004). El arte del olvido: y tres ensayos sobre mujeres. Buenos Aires: Beatriz Viterbo.

SCHOWOB, M. (1998). "El arte de la biografía". En Vidas imaginarias, 25-33. Buenos Aires: Emecé.

TODOROV, T. (1978). Teoría de los géneros literarios. Madrid: Arco / Libros.

VILLANUEVA, Darío (1991). "Para una pragmática de la autobiografía". En La autobiografía en lengua española en el siglo veinte, VV.AA., 201-218. Lausane: Hispánica Helvética.

(1993). "Realidad y ficción: la paradoja de la autobiografía". En Escritura autobiográfica, J. Romera Castillo (ed.), 15-33. Madrid: Visor Libros.

WITTGENSTEIN, L. (1977). Investigaciones filosóficas. Barcelona: Crítica. (1992). Sobre la certeza. Barcelona: Gedisa.

Recibido el 8 de enero de 2019.

Aceptado el 28 de febrero de 2019. 